\title{
Modeling the Operation of a Galvanic Bath with Electric Heaters and Optimizing its Design Based on Numerical Simulation
}

\author{
Alexander Samarkin \\ Institute of Medicine and Biology \\ Pskov State University \\ Pskov, Russia \\ Alexsamarkinru@gmail.com \\ Evegeniya Evgenyeva \\ Institute of Engineering Sciences \\ Pskov State University \\ Pskov, Russia \\ zhen_sheny@mail.ru
}

\author{
Sergey Dmitriev \\ Institute of Engineering Sciences \\ Pskov State University \\ Pskov, Russia \\ dmitrievsi55@gmail.com \\ Elena Samarkina \\ Institute of Engineering Sciences \\ Pskov State University \\ Pskov, Russia \\ ElenaSPsk@gmail.com
}

\author{
Alexander Dementyev \\ Institute of Engineering Sciences \\ Pskov State University \\ Pskov, Russia \\ damix01@yandex.ru
}

A model of the processes in a galvanic bath during heating is based on the finite element method. The processes of heating the air chamber and directly the reagent solution are simulated. Based on the constructed model, an automatic control system for heating elements is being developed, which provides a sufficient heating rate, a stable temperature and protects the heating elements from burnout. An application program has been created that allows performing the calculations without studying complex modeling systems.

Keywords - automated controls, computed fluid dynamics, finite element analysis.

\section{INTRODUCTION}

Formulation of the problem. The enterprises of the region are interested in using medium-sized galvanic bathtubs (width - $800 \mathrm{~mm}$, length - 1000-1400 mm, bath height - $400 \mathrm{~mm}$ ) to apply resistant coatings. During the process, it is necessary to maintain the temperature of the solution 35-500C, which involves heating the solution.

The most popular is the design with a bathtub, under which electric heating elements (heating elements) are in a thermally insulated compartment [1]. The length of the working part of the heating element (about $700 \mathrm{~mm}$ ) determines the maximum width of the bathtub. The length of the bath is determined by the number of heating elements and the distance between them. Features of production do not allow to change the distance between the axes of the heating elements.

During operating the bathtubs, several negative phenomena are observed associated with increased failure of the heating elements during the initial heating of the bath solution (during operation, the temperature of the solution is maintained by a separate control system). It was established experimentally that the heating element burns out when its working surface is heated above a certain temperature, which is $T_{k r}=820^{\circ} \mathrm{C}$ for the most common heating element in production and works in such conditions for over 15 minutes. Used in manufacturing heaters are precision alloys with high electrical resistance [2]. These include alloys based on chromium and nickel (chromium-nickel), iron, chromium, and aluminum (chromium-aluminum). The grades and properties of these alloys are considered in GOST 10994-74 "Precision alloys. Stamps." [3] Representatives of chromium-nickel alloys are nichrome of the grades Cr20Ni80, Cr20Ni80-H (950$\left.1200^{\circ} \mathrm{C}\right), \mathrm{Cr} 15 \mathrm{Ni} 60$, Cr15Ni60-H $\left(900-1125^{\circ} \mathrm{C}\right)$, ironchromium-aluminum alloys - fechral of the grades Cr23Al5Ti $\left(950-1400^{\circ} \mathrm{C}\right), \mathrm{Cr} 27 \mathrm{Al} 5 \mathrm{Ti}\left(950-1350^{\circ} \mathrm{C}\right)$, Cr23Al5 (950-1200 $\left.{ }^{\circ} \mathrm{C}\right), \mathrm{Cr} 15 \mathrm{Al} 5\left(750-1000^{\circ} \mathrm{C}\right)$. In the modern market, fechral is cheaper than nichrome at least 35 times at the price of a kilogram of the semi-finished products. This is because the cost of nickel, which is the basic element of nichrome, is an order of magnitude higher than the cost of iron - the basis of fechral. 
The task is to increase the resistance of the heating element by optimizing the algorithm for primary heating of the bath solution [4].

\section{MATERIALS AND METHODS}

Ways and methods of solving. Possible ways are:

1. Placement of heaters in contact with the galvanic solution.

2. Changing the structural implementation of the bottom of the bath by fins, blackening of surfaces to improve heat dissipation and achieve temperature equilibrium below the point $T_{k r}$.

3. Connection of a control system capable of connecting the heaters discretely or changing its operating temperature continuously.

The first option is impossible since the galvanic solution has high chemical activity. There are also sanitary and technological requirements for the complete tightness of the bath.

Changing the design of the bath is also difficult, as it entails a change in the process and significant costs.

The control system is inexpensive to implement, allows you to implement both fairly complex logic when implemented on industrial controllers and integrate the product into an automated quality control system or remote control, and is simple [5].

Control System can be implemented:

1. With discrete control of the turn-on time parameter of the heating element without temperature feedback.

2. With discrete control of the turn-on time parameter of the heating element with temperature feedback.

3. With continuous power control of the heating element (from $0 \%$ - off, up to $100 \%$ - turned on at full power).

The first option involves turning on / off the heaters according to a predetermined algorithm. It is relatively simple to implement, but it does not allow to control the actual operating conditions of the heaters.

Option 2 involves the installation of a temperature sensor with a direct or indirect measurement method, and it is difficult to directly measure the temperature of the heater with a sensor.

The third option is relatively complex and potentially the most flexible, however, the power consumption is controlled either by a switching power supply, which is difficult with a heater power of about $5 \mathrm{~kW}$, or by a parasitic load, which reduces the efficiency of the installation.

Thus, we choose for further implementation of a system with discrete heater control and temperature feedback.
Feedback must control the process. The controlled parameter is the surface temperature of the heating element, however, its direct measurement is difficult, so we measure the temperature in an indirect way, namely through the air temperature in the heating zone.

To implement this control method, it is proposed to simulate heating the bath by numerical methods, using the model of the bath and the heater by the finite element method [6].

Process simulation. Bath heating and cooling

Since all bath cross-sections from the viewpoint of temperature distribution and fluid flow can be considered the same, we restrict ourselves to a two-dimensional statement of the problem.

To build the simplest model, we estimate the time of heating the solution in the bath from a temperature of 200C to a working temperature of 500C. A comparison of the calculation results of this model with practice will allow us to evaluate its adequacy. Below is a sketch of the crosssection of the bath and the grid of finite elements.
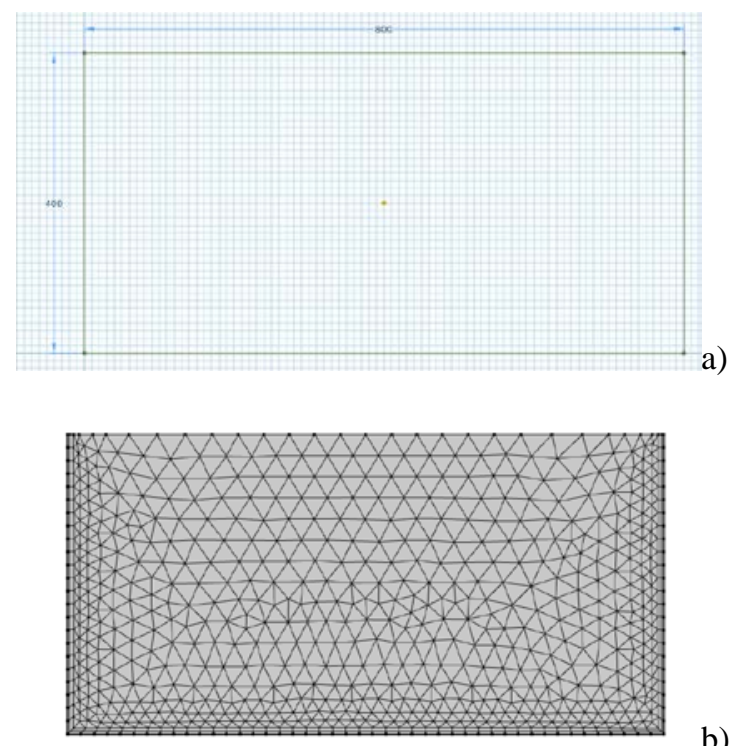

b)

Fig. 1. Galvanic bath cross-section sketch (dimension in $\mathrm{mm}$ ) with finite-element $2 \mathrm{~d}$ mesh.

Suppose that the upper plane and side walls undergo natural convection into the air with an ambient temperature of 200C. Heating is carried out by supplying heat to the lower plane of the drawing (Fig. 1).

Technical documentation (https://polymernagrev.ru/catalog/elektricheskieteny/bloki-tenov/) for the used heaters gives: maximum diameter $d_{\max }=18 \mathrm{~mm}$, length $l=700 \mathrm{~mm}$, specific power - $p_{u d}=15 \frac{\mathrm{W}}{\mathrm{cm}^{2}}$, whence the power of the 1st tube $P_{1}=p_{u d} \pi d_{\text {max }} l=5900 \mathrm{~W}$

Since $k=8$ heaters are used for the size understudy, they are located at an equal distance from each other, and taking into account that air heating losses are (for 
Environment. Technology. Resources. Rezekne, Latvia Proceedings of the $13^{\text {th }}$ International Scientific and Practical Conference. Volume 3, 330-335

reference) $\mu=30 \%$, we obtain the net heating power $P=(1-\mu) k P_{1}=33 k W$.

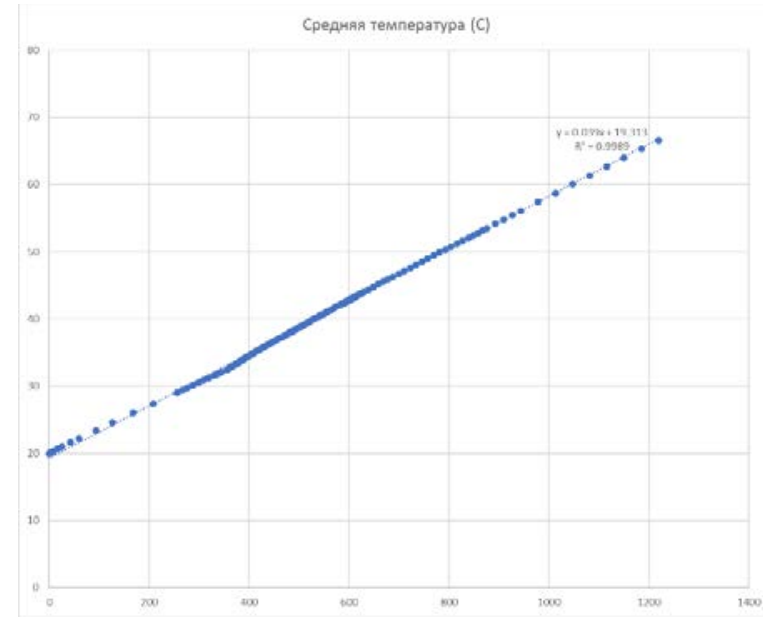

Fig. 2. Modeling the heating process using various mathematical models of heating a plating bath: Low-Re $k-\varepsilon$ model.

Several numerical models describe the flow of a fluid due to a change in its density under the influence of temperature. The most used are the model with the laminar and turbulent flow (having several formulations) (See results at Fig. 2) [7]. The laminar model might consider the effects of mixing, and the turbulent model becomes ineffective at low flow rates, however, turbulent models are necessary to describe the flows arising from mixing of hot and cold fluids, and the behaviour of media in the layers near the walls [8].

Bath heating with an electric heater

To increase the productivity of calculations, we use the assumption stated above that all bath sections are characterized by the same picture of heat transfer processes, which include the transfer of thermal energy and the turbulent flow of air and a galvanic solution. This allows us to pose the problem in a two-dimensional formulation.

Divide the flat section of the bath into departments above the heaters. Because we are interested in the process of heating, we can neglect the processes of flow near the walls and consider all such departments to be the same. It is also obvious that the left and right halves of each department are symmetrical both geometrically and from the viewpoint of the processes in them, which gives us reason to consider further only this half (see Fig. 3).

The presented geometry can be easily parameterized to obtain a generalized solution. The main parameters determining the geometry will be the width of the section, the height of the air chamber and the bath, the diameter of the heater, its position (height) in the air chamber, the power taken from the unit area of the outer surface of the heater, and the width of the bath. Parameter names are given under the rules for naming variables in the Java programming language and further they are used as variables of the developed specialized software (see Table 1).

TABLE 1 MODEL PARAMETERS

\begin{tabular}{|c|c|c|c|c|}
\hline Parameter & Designation & Value & Units & Note \\
\hline Bath width & len1 & 700 & {$[\mathrm{~mm}]$} & $\begin{array}{c}\text { According } \\
\text { specs }\end{array}$ \\
\hline $\begin{array}{c}\text { Heater } \\
\text { diameter }\end{array}$ & diam1 & 18 & {$[\mathrm{~mm}]$} & $\begin{array}{c}\text { According } \\
\text { specs }\end{array}$ \\
\hline $\begin{array}{c}\text { Heater center } \\
\text { offset }\end{array}$ & dy1 & 20 & {$[\mathrm{~mm}]$} & $\begin{array}{c}\text { According } \\
\text { technical } \\
\text { drawing }\end{array}$ \\
\hline Section Width & b1 & 100 & {$[\mathrm{~mm}]$} & \\
\hline $\begin{array}{c}\text { Air } \\
\text { Compartment } \\
\text { Height }\end{array}$ & h1 & 120 & {$[\mathrm{~mm}]$} & \\
\hline Bath height & h2 & 400 & {$[\mathrm{~mm}]$} & \\
\hline $\begin{array}{c}\text { Heater } \\
\text { specific power }\end{array}$ & pwr1 & 15 & {$\left[\mathrm{~W} / \mathrm{cm}^{\wedge} 2\right]$} & $\begin{array}{c}\text { According } \\
\text { specs }\end{array}$ \\
\hline Loss ratio & $\mathrm{kp}$ & 0.3 & - & \\
\hline $\begin{array}{c}\text { Useful } \\
\text { specific }\end{array}$ & pwr2 & $\begin{array}{c}(1- \\
\mathrm{kp})^{*} \text { pwr1 }\end{array}$ & {$\left[\mathrm{W} / \mathrm{cm}^{\wedge} 2\right]$} & \\
\hline Heater power & Tmax1 & 950 & {$[\operatorname{deg} \mathrm{C}]^{0} \mathrm{C}$} & \\
\hline $\begin{array}{l}\text { Maximum } \\
\text { permissible }\end{array}$ & Tmin1 & 300 & {$[\operatorname{deg} \mathrm{C}]{ }^{0} \mathrm{C}$} & \\
\hline
\end{tabular}

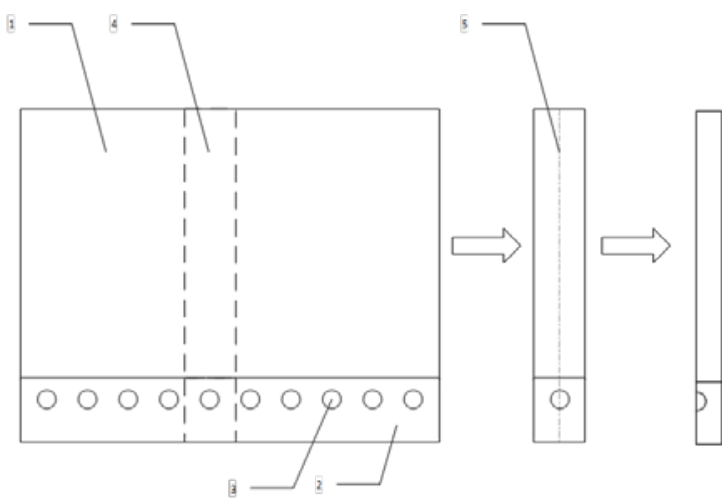

A)

Fig. 3. Simplification of a galvanic bath model A) - flat cross-section (1 - bath, 2 - air chamber, 3 - heater, 4 - repeated section), B) symmetric repeated section (5 - axis of symmetry), C) - half of a repeated section/

\section{Continuous heater heating model}

In the simplest case, when the heater is turned on on its outer surface with a certain time delay (this delay is necessary to obtain a convergent solution and is modeled as a ramp function - rise with saturation from the time it was turned on and is used later for all power turns on).

Thus, the specific power per unit area $P_{u d}(t)$ as a function of the turn-on time $\mathrm{t}$ is: $P_{u d}=P_{0}$ ramp $(t)$, where $P_{0}$ is the useful specific power of the heater pwr2 (Table 1), and the function $\operatorname{ramp}(t)$ is defined as: $\operatorname{ramp}(t)=\left\{\begin{array}{c}0, t \leq 0 \\ k t, t>0 \\ 1, k t \geq 1\end{array}\right.$

In the simulation, besides the Low-Re k- $\varepsilon$ model, a normal-quality mesh with default settings is used, 
excluding the number of wall layers increased to 5 , a fragment of which is shown in Fig. 4, with the temperature and velocity distribution diagram.

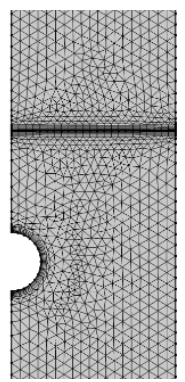

a)

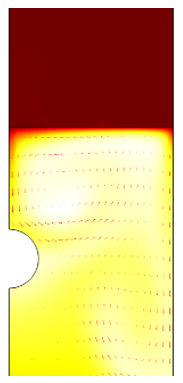

b)

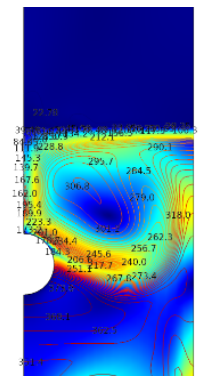

Fig. 4. a) - mesh of finite elements, b) - temperature distribution diagram, arrows - velocity field vector, c) - velocity distribution diagram, with contours as isotherms

The simulation results in terms of heating time agree with the experiment and the previous model of bath heating (about 14 minutes for heating to $50^{\circ} \mathrm{C}$ ). Then everywhere we take the total bath heating time $T_{\text {all }}=15 \mathrm{~min}$.

To control the temperature of the heater, the wall of the bathtub and the galvanic solution, the model includes domain and averaging sensors (domain probe and boundary probe, respectively) that integrate the temperature and guarantee smooth first and second time derivatives (this converges the solution), the plot of the readings of which is presented below.

\section{A heating model with periodic timer activation}

Since the approximate heating time is 15 minutes, as a first approximation, a decision was made to apply power by cycling the heater on and off. The cycle time is 6 minutes, of which 4 minutes the heater works.

Graphs of sensor readings and separately the average bath temperature is presented below at Fig. 5.
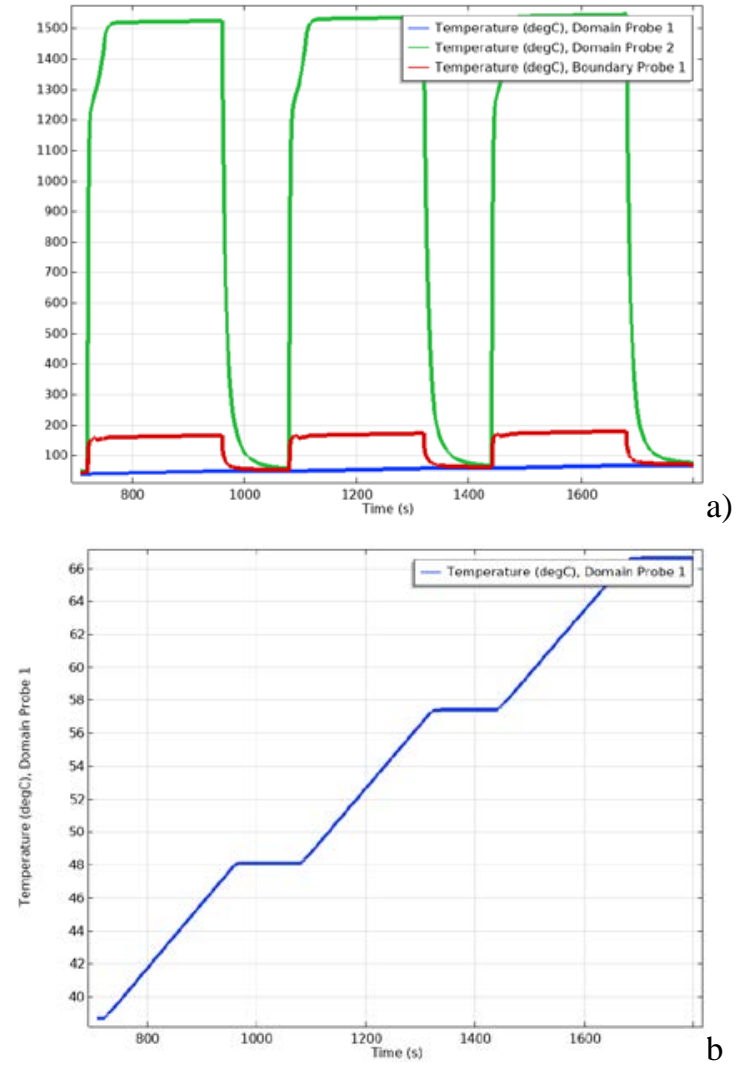

Fig. 5. Simulation of bath heating during periodic switching on of the heater a) - graphs of the temperature of the heater (green line), the bottom surface of the bath (red), solution (blue), b) - the average temperature of the galvanic solution

Note that for modeling on-off processes, it is necessary to use not only the traditional finite element model but also supplement it with a discrete state model. The specific way to implement such a system can be different, for example, ANSYS Fluent, in this case, involves writing custom functions () in $\mathrm{C}++$.

In a system like Comsol [7], there are more convenient tools a discrete state mechanism and explicit events. See below for more details. Figure 6

Explicit events occur at the onset of sometime and control state variables. The model uses a single ONOFF variable that takes the values 1 (on) and 0 (off). Events are formulated in such a way that at the beginning of the cycle the variable is set to 1 , and after 4 minutes of operation, it is set to 0 until the end of the 6-minute cycle, after which everything repeats.

To turn on to operating temperature three switch-on is required, the solution overheating to 66 degrees, and the heater operates at extreme temperatures of $80 \%$ of the turnon time, about 3 minutes per cycle, which is considered acceptable (the continuous operation is allowed up to 15 minutes, see the introduction to the article).

The heating model with the control of the upper and lower limit of the heater temperature. 
Environment. Technology. Resources. Rezekne, Latvia Proceedings of the $13^{\text {th }}$ International Scientific and Practical Conference. Volume 3, 330-335

More effective, although more complex, is the implementation of the heating process with feedback on the temperature of the heater (see [9] about theory). Here, the model uses implicit (implicit) event management. An element of control over the temperature of the heater is introduced into the model in indicator states (see indicator of states at Fig. 6).

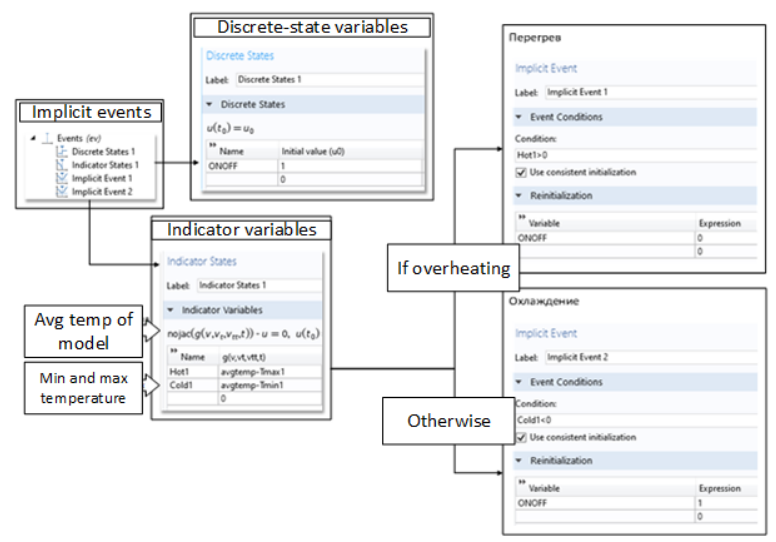

Fig. 6. Heater control using implicit events

The indicated indicator receives the average temperature of the heater through the integral operator and compares it with two parameters - the maximum upper and lower temperatures of the heater, set as parameters. Thus, a feedback effect is achieved, however, the values of the temperature boundaries require adjustment. The upper limit is determined from the condition of resistance of the heater. The lower limit is reached after turning off the power and, thus, its value determines the time the heater is turned off. Let, as a first approximation, the values of the parameters according to Table 2 .

TABLE 2 CyCLE PARAMETERS (1-ST ATTEMPT)

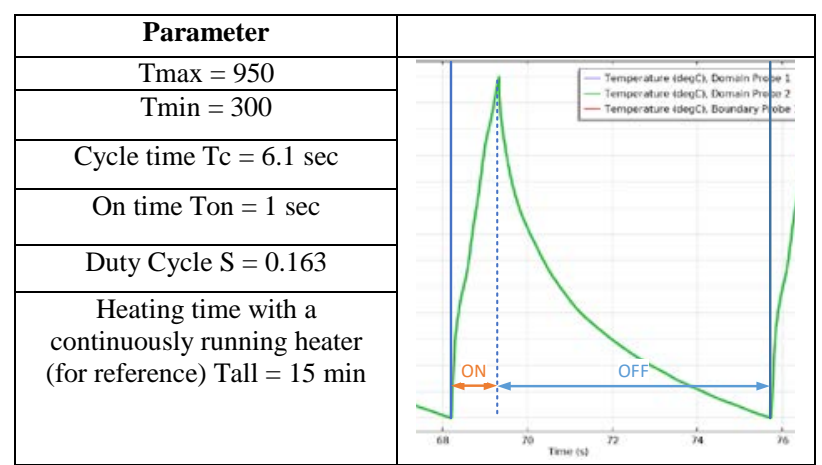

Since the duty cycle is $16.3 \%$, the bath heating time will be $T=\frac{T_{\text {all }}}{\mathrm{S}}=91.5 \mathrm{~min}$.

We take the temperature of inclusion $60^{\circ} \mathrm{C}$ (Table 3).
TABLE 2 CYCLE PARAMETERS (ADJUSTED)

\begin{tabular}{|c|}
\hline Parameter \\
\hline Tmax $=950$ \\
\hline Tmin $=600$ \\
\hline Cycle time Tц $=2,8$ сек \\
\hline On time Ton $=0,75$ сек \\
\hline Duty Cycle S $=0.27$ \\
\hline $\begin{array}{c}\text { Heating time with a continuously running heater (for reference) Tall } \\
=15 \text { min }\end{array}$ \\
\hline
\end{tabular}

Since the duty cycle this time is $26.9 \%$, the bath heating time will be $T=\frac{T_{\text {all }}}{\mathrm{S}}=56 \mathrm{~min}$.

Thus, by adjusting the lower limit for turning on the heater, it was possible, due to a production-acceptable increase in the heating time of the bathtub, to ensure guaranteed operation of the heater in the modes recommended for heating elements.

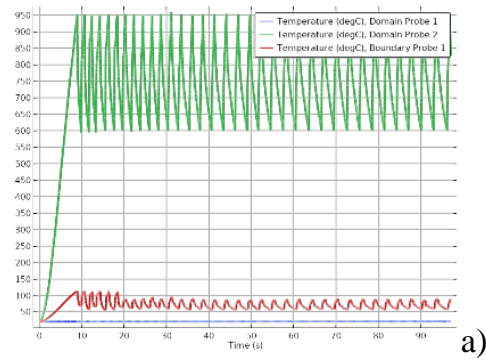

a)

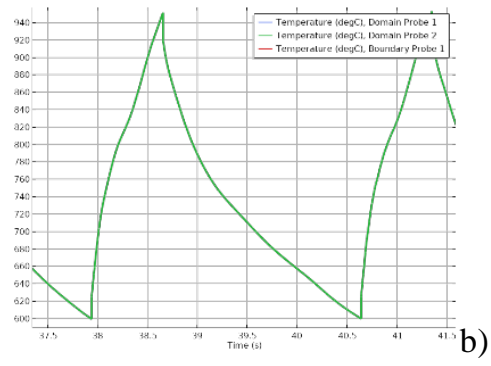

Fig. 7. Temperature diagram by on-off cycle with adjusted parameters (according Table 3), where a) - full-time diagramm, b) - one-cycled diagram.

\section{RESULTS AND DISCUSSION}

Generalized model

Due to the need to manufacture bathtubs for special orders, an application based on the presented calculations has been developed. The interface of the application presented below (see Fig. 8).

By changing the parameters, it is possible to change both the geometry of the section and the parameters of the heater and the control modes over the heating process (through the maximum and minimum temperatures).

Thus, as a result of the work, it was possible to calculate a complex problem, including the calculation of heat transfer and turbulent mixing of liquid and gas in interacting domains. 


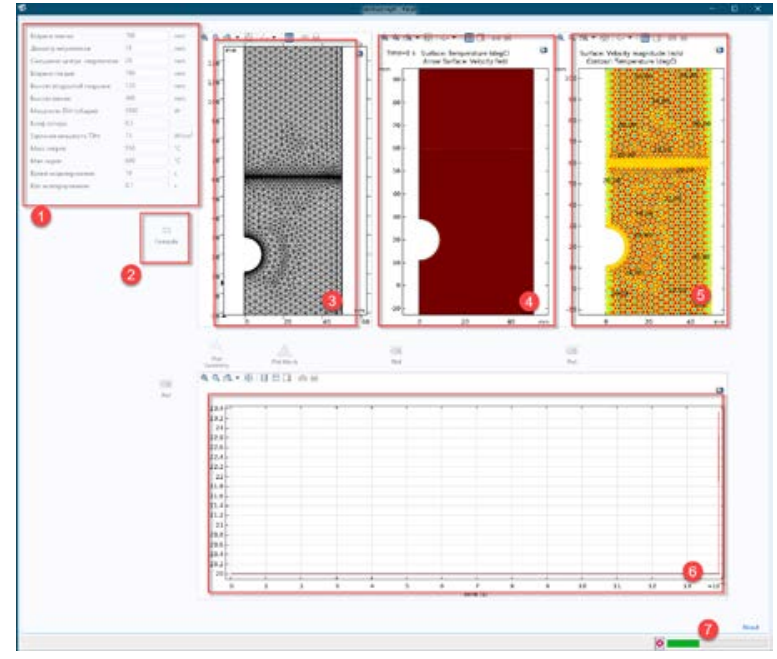

Fig. 8. Application interface, 1 - area for setting parameters, 2 - button for sending a task for calculation, 3 - area for display constructing geometry or a mesh of finite elements, 4 - temperature plot in the heating zone (dynamically rebuilds during the calculation), 5 - speed diagram in the heating zone ( based on the calculation results), 6 average domain temperatures (dynamically rebuilds).

\section{CONCLUSIONS}

Numerical modeling tools allow you to solve very complex problems, and thanks to the possibility of creating "digital doubles", it is possible to reduce the production test time to a minimum, which drastically reduces the cost of modernization and implementation of new products.

Under consideration, it was possible to implement such operating modes of fechral heating elements that realize their advantages and level their disadvantages. It was possible to reduce the cost of purchased electrodes by 2-3 times while maintaining high product quality.

\section{ACKNOWLEDGMENTS}

The work was performed on the provided trial version of the COMSOL Multiphysics program (https://www.comsol.ru/).

\section{REFERENCES}

[1] M. Hejfec, V. Borodavko, V. Ivashko, and S. Klimenko, Obrabotka i uprochnenie poverhnostej pri izgotovlenii i vosstanovlenii detalej: LitRes, 2021. [Online]. Available: https://books.google.ru/books?id=DFsVEAAAQBAJ

[2] ELEKTRONAGREVATELI TRUBCHATYE, 13268-88, GOSUDARSTVENNYJ STANDART SOYUZA SSR, M. 01/01/90.

[3] SPLAVY PRECIZIONNYE, 10994-74, MEZHGOSUDARSTVENNYJ STANDART, M., 01/01/75.

[4] V. Sheleg, K. avtorov, and M. Kane, Tekhnologiya mashinostroeniya. Kursovoe proektirovanie: LitRes, 2017. [Online]. https://books.google.ru/books?id=TI0QDQAAQBAJ

[5] V. YAkuhin, Vysokotekhnologichnye metody metalloobrabotki. Uchebnik: Izd-vo MGIU, 2011. [Online]. Available: https://books.google.ru/books?id=sdZbma80B9oC

[6] P. D. Bates, S. N. Lane, and R. I. Ferguson, Computational fluid dynamics: Applications in environmental hydraulics. Hoboken, NJ: J. Wiley, 2010. [Online]. Available: http://search.ebscohost.com/login.aspx?direct=true\&scope=site\& $\mathrm{db}=$ nlebk\&db=nlabk\&AN=138344

[7] M. Tabatabaian, COMSOL for engineers. Dulles, VA: Mercury Learning and Information, 2014. [Online]. Available: http://search.ebscohost.com/login.aspx?direct=true\&scope=site\& $\mathrm{db}=$ nlebk\&AN $=1809110$

[8] R. W. Pryor, Multiphysics modeling using COMSOL5 and MATLAB. Dulles: Mercury Learning and Information, 2016.

[9] N. V. Sahinidis, “Mixed-integer nonlinear programming 2018," Optim Eng, vol. 20, no. 2, pp. 301-306, 2019, doi: 10.1007/s11081019-09438-1. 